\title{
Subclinical Hypothyroidism and Intracytoplasmic Sperm Injection Outcomes
}

\section{Hipotireoidismo subclínico e resultados de Injeção intracitoplasmática de espermatozoide}

\author{
Marcela de Alencar Coelho Neto ${ }^{1}$ Wellington de Paula Martins ${ }^{1}$ Anderson Sanches de Melo ${ }^{1}$ \\ Rui Alberto Ferriani ${ }^{1}$ Paula Andrea Navarro ${ }^{1}$ \\ ${ }^{1}$ Department of Obstetrics and Gynecology, Faculdade de Medicina \\ de Ribeirão Preto, Universidade de São Paulo (DGO-FRMP-USP), \\ Ribeirão Preto, SP, Brazil \\ Address for correspondence Marcela A. Coelho Neto, MD, \\ Universidade de São Paulo, Av. Bandeirantes 3900, 8 andar, HCRP, \\ Campus Universitário, 14049-900, Ribeirão Preto, SP, Brazil \\ (e-mail: marcelalencar@hotmail.com).
}

Rev Bras Ginecol Obstet 2016;38:552-558

\begin{abstract}
Keywords

- thyrotropin (TSH)

- subclinical hypothyroidism

- intracytoplasmic sperm injection (ICSI)

- live birth

- miscarriage
\end{abstract}

Purpose Whether preconception elevated concentrations of thyroid-stimulating hormone (TSH) compromises reproductive outcomes in patients undergoing assisted reproduction techniques (ARTs) remains unclear. This study therefore compared the reproductive outcomes in patients with TSH concentrations of $<2.5 \mathrm{mIU} / \mathrm{L}, 2.5-4.0$ $\mathrm{mIU} / \mathrm{L}$, and 4.0-10.0 mIU/L undergoing controlled ovarian stimulation (COS) for in vitro fertilization (IVF)/intracytoplasmic sperm injection (ICSI).

Methods This retrospective cohort study evaluated the medical records of all women with measured TSH concentrations who underwent IVF/ICSI between January 2011 and December 2012. The patients were divided into three groups: TSH $<2.5 \mathrm{mlU} / \mathrm{L}$ (group 1); THS $\geq 2.5$ and $<4.0 \mathrm{mIU} / \mathrm{L}$ (group 2); and THS $\geq 4 \mathrm{mlU} / \mathrm{L}$ and $<10.0 \mathrm{mlU} / \mathrm{L}$ (group 3). Patients who were administered levothyroxine for treating hypothyroidism were excluded from the analysis. The primary endpoints were clinical pregnancy, miscarriage, live birth and multiple pregnancy rates.

Results During the study period, 787 women underwent IVF/ICSI. Sixty were excluded because their TSH concentrations were unavailable, and 77 were excluded due to their use of levothyroxine. The prevalence of patients presenting elevated concentrations of TSH was of $5.07 \%$ (using a TSH threshold of $4.0 \mathrm{mIU} / \mathrm{L}$ ) and of $29.99 \%$ (using a TSH threshold of 2.5 $\mathrm{mIU} / \mathrm{L}$ ). Patient characteristics, type of COS, and response to COS did not differ among the three groups, and there were no differences in clinical pregnancy ( $24.4 \%$ versus $25.9 \%$ versus $24.2 \%, p=0.93)$; miscarriage $(17.1 \%$ versus $14.3 \%$ versus $12.5 \%, p=0.93)$; live birth $(20.2 \%$ versus $22.2 \%$ versus $21.2 \%, p=0.86)$; and multiple pregnancy rates $(27.0 \%$ versus $21.4 \%$ versus $25.0 \%, p=0.90$ ) respectively.

Conclusion Response to COS, live birth, and miscarriage rates were not altered in women with elevated concentrations of TSH undergoing IVF/ICSI, regardless of using a TSH threshold of $2.5 \mathrm{mIU} / \mathrm{L}$ or $4.0 \mathrm{mIU} / \mathrm{L}$. These findings reinforce the uncertainties related to the impact of subclinical hypothyroidism on reproductive outcomes in women undergoing COS for ARTs. received

June 14, 2016

accepted

September 29, 2016

published online

November 16, 2016
Copyright $\odot 2016$ by Thieme-Revinter

Publicações Ltda, Rio de Janeiro, Brazil
License terms

(c) (i) $\ominus$ (\$) 10.1055/s-0036-1593986. ISSN 0100-7203. 


\section{Resumo}

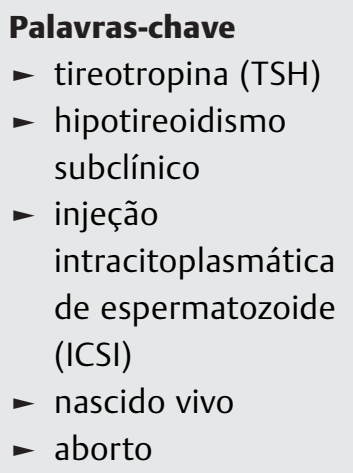

Objetivos Se concentrações elevadas de hormônio estimulante da tireoide (TSH) antes do parto comprometem resultados reprodutivos em pacientes submetidas a técnicas de reprodução assistida (TRA) é incerto. Este estudo comparou resultados reprodutivos de pacientes com concentrações de TSH $<2,5 \mathrm{mIU} / \mathrm{L} ; 2,5-4,0 \mathrm{mIU} / \mathrm{L}$ e 4,0-10,0 mIU/L submetidas a estimulação ovariana controlada (EOC) para fertilização in vitro (FIV)/injeção intracitoplasmática de espermatozoide (ICSI).

Métodos Este estudo de coorte retrospectiva avaliou prontuários médicos de todas as pacientes que tinham registro de concentrações de TSH submetidas a FIV/ICSI entre janeiro de 2011 e dezembro de 2012. As pacientes foram divididas em três grupos: aquelas com TSH $<2,5 \mathrm{mIU} / \mathrm{L}$ (grupo 1); entre 2,5 e 4,0 mIU/L (grupo 2) e entre 4,0 $\mathrm{mIU} / \mathrm{L}$ e $10,0 \mathrm{mIU} / \mathrm{L}$ (grupo 3 ). As pacientes que estavam em uso de levotiroxina para tratamento de hipotireoidismo foram excluídas da análise. Os desfechos primários foram taxas de gravidez clínica, de abortamento, de nascido vivo e de gravidez múltipla.

Resultados Durante o período do estudo, 787 mulheres foram submetidas a FIV/ICSI. Sessenta foram excluídas por causa da indisponibilidade das concentrações de TSH, e 77 foram excluídas porque estavam usando levotiroxina. A prevalência de pacientes apresentando elevação das concentrações de TSH foi de 5,07\% (usando um limite de TSH de 4,0 mIU/L) e 29,99\% (usando um limite de TSH de 2,5 mIU/L). As características das pacientes, tipo de EOC e reposta à EOC não diferiram entre os três grupos, nem houve diferenças nas taxas de gravidez clínica ( $24,4 \%$ versus $25,9 \%$ versus $24,2 \%$, $p=0,93$ ); abortamento ( $17,1 \%$ versus $14,3 \%$ versus $12,5 \%, p=0,93$ ); nascido vivo $(20,2 \%$ versus $22,2 \%$ versus $21,2 \%, p=0,86)$; e taxas de gestação múltipla $(27,0 \%$ versus $21,4 \%$ versus $25,0 \%, p=0,90$ ), respectivamente.

Conclusão Resposta à EOC, taxa de nascido vivo e de abortamento não foram alteradas em mulheres submetidas a FIV/ICSI com concentrações elevadas de TSH independente de usar um limite de 2,5 ou 4,0 mIU/L. Estes achados reforçam as incertezas relacionadas ao impacto do hipotireoidismo subclínico nos resultados reprodutivos de mulheres submetidas a EOC para TRA.

\section{Introduction}

Female infertility accounts for $37 \%$ of infertile couples, with $25 \%$ of these women having ovulatory disorders. ${ }^{1}$ Women with thyroid dysfunction may experience ovulatory disorders, menstrual irregularities, infertility and even increased pregnancy morbidity. ${ }^{2}$ Elevated concentrations of thyroid stimulating hormone (TSH) in asymptomatic patients may also increase the likelihood of pregnancy complications, ${ }^{3-5}$ neonatal mortality ${ }^{4}$ and miscarriage. ${ }^{6,7}$

Until recently, human reproduction societies did not recommend the measurement of TSH concentration in asymptomatic ovulatory women, ${ }^{8,9}$ but the new guideline published by the American Society for Reproductive Medicine (ASRM) endorses dosing TSH in infertile women attempting pregnancy. ${ }^{7}$ The American Thyroid Association (ATA) recognizes that the prevalence of thyroid dysfunction is higher in subfertile women, ${ }^{5}$ while the Endocrine Society recommends measuring TSH in patients at "high risk" of thyroid illness, including asymptomatic infertile ones. ${ }^{3}$ Furthermore, there is no consensus among endocrinologists and gynecologists regarding the cut-off
TSH concentrations for patients pursuing pregnancy, whether $<2.5 \mathrm{mIU} / \mathrm{L}^{3}$ or $<4.0 / 4.5 \mathrm{mIU} / \mathrm{L}^{7,10-14}$

For patients who will undergo assisted reproduction techniques (ARTs), the high estradiol levels induced by controlled ovarian stimulation (COS) may alter thyroid function by increasing the concentrations of TSH, with hypothyroid women being most affected. ${ }^{15-17}$ Nevertheless, it is unclear whether the preconceptional concentration of TSH or the elevations in TSH concentration during COS are relevant in infertile women undergoing ARTs. ${ }^{18}$ This study, therefore, has compared reproductive outcomes in patients with serum TSH concentrations of $<2.5 \mathrm{mIU} / \mathrm{L}, 2.5-4.0 \mathrm{mIU} /$ $\mathrm{L}$, and $4.0-10.0 \mathrm{mIU} / \mathrm{L}$ undergoing COS for in vitro fertilization (IVF)/intracytoplasmic sperm injection (ICSI).

\section{Methods}

\section{Study Design}

This retrospective cohort study evaluated all women who underwent IVF/ICSI at the fertility clinic of the university hospital of the Faculdade de Medicina de Ribeirão Preto, 
Universidade de São Paulo, Brazil, between January 2011 and December 2012. Data were obtained from medical records. The study protocol was approved by the Institutional Review Board.

\section{Participants}

Women who had undergone IVF/ICSI between January 2011 and December 2012 were eligible if they had serum TSH concentrations evaluated by a third-generation assay reported in their medical records. Patients in treatment with levothyroxine for hypothyroidism were excluded from the analysis.

In spite of the fact that the concentrations of TSH $\geq 4.0 \mathrm{mIU} /$ $\mathrm{L}$ and $<10 \mathrm{mIU} / \mathrm{L}$ in asymptomatic patients are classically used to define subclinical hypothyroidism, ${ }^{6,10-14,19}$ patients with $\mathrm{TSH}<4.0 \mathrm{mIU} / \mathrm{L}$ were divided into two subgroups (TSH $<2.5$ $\mathrm{mIU} / \mathrm{L}$ and TSH $2.5-4.0 \mathrm{mIU} / \mathrm{L}$ ). For comparison, three groups were divided: those with TSH $<2.5$ (group 1 ); TSH $>2.5 \mathrm{mIU} / \mathrm{L}$ and $>4.0 \mathrm{mIU} / \mathrm{L}$ (group 2); and TSH $>4.0 \mathrm{mIU} / \mathrm{L}$ and $<10.0$ $\mathrm{mIU} / \mathrm{L}$ (group 3).

\section{COS, Oocyte Retrieval, Fertilization and Embryo Transfer}

Menstruation was programmed with combined oral contraceptives administered in the previous menstrual cycle. All women were subjected to COS monitored by transvaginal ultrasound (TVUS) ${ }^{20}$ according to one of the following protocols:

In the standard long protocol, gonadotropin-releasing hormone (GnRH) agonists (leuprolide acetate $0.5 \mathrm{mg} /$ day, Lupron, Famar L'Aigle, Saint-Remy-Sur-Avre, France) were introduced during the mid-luteal phase of the previous cycle, followed by 150-300 IU/day of gonadotropins (Gonal-F, Merck Serono, Geneva, Switzerland, or Puregon, Organon, Oss, Holland) for the first six days. Subsequently, the daily dose of gonadotropins was adjusted according to follicular growth.

In the flexible antagonist protocol, gonadotropins (150-300 IU/day) were administered for the first six days, with a subsequent daily dose adjusted according to follicular growth. Gonadotropin-releasing hormone antagonists $0.25 \mathrm{mg} /$ day (Ganirelix, Orgalutran, Organon, Dublin, Ireland, or Cetrorelix, Cetrotide, Merck Serono, Geneva, Switzerland) were introduced on the day the average diameter of the largest follicle was $\geq 14 \mathrm{~mm}$.

In the clomiphene citrate (CC) (Clomid, Medley, Campinas, Brazil, or Indux, EMS, Campinas, Brazil) plus gonadotropins (Menopur, Ferring GmbH, Kiel, Germany) plus antagonist protocol, offered to women with a low antral follicle count $(\mathrm{AFC} \leq 6),{ }^{21} \mathrm{CC}(100 \mathrm{mg} /$ day $)$ was administered for the first five days. Gonadotropins (150 IU/day) were administered on days 2 and 4, and daily after day 6. Gonadotropin-releasing hormone antagonists were introduced when the average diameter of the largest follicle was $\geq 14 \mathrm{~mm}$.

Recombinant (Ovidrel, Merck Serono, Modugno, Italy) or urinary (Choriomon, IBSA Institut Biochimique, S.A., Lamone, Switzerland) human chorionic gonadotropin (hCG) was administered when at least two follicles measuring $18 \mathrm{~mm}$ in diameter were present. Oocytes were retrieved 34 to 36 hours after hCG administration, and the luteal phase was supported by micronized progesterone, $600 \mathrm{mg} /$ day (Utrogestan, Besins Manufacturing Belgium, Drogenbos, Belgium). Cycles were suspended due to poor response when no follicle reached a diameter of $10 \mathrm{~mm}$ after ten days of COS or after 4 to 5 days of additional treatment without any follicle measuring at least $18 \mathrm{~mm}$ in diameter. ${ }^{22}$

The obtained oocytes were incubated at $37^{\circ} \mathrm{C}$ in $5 \% \mathrm{CO}_{2}$ and $95 \%$ humidity for 2-3 hours, and later on denuded by hyaluronidase. Mature oocytes were subjected to ICSI 3 to 4 hours after oocyte retrieval. Fertilization was evaluated 16 to 18 hours after the ICSI and defined as the presence of two pronuclei and two polar bodies.

Embryo quality was assessed 43 to 45 hours after the ICSI (day 2 embryos with 4 symmetrical blastomeres of normal size, $<10 \%$ of fragmentation, without multinucleation, were considered of top quality), or 67 to 69 hours after the ICSI (day 3 embryos with 8 symmetrical blastomeres of normal size, $<10 \%$ of fragmentation, without multinucleation, were considered of top quality). ${ }^{23}$

The rate of clinical pregnancy was defined as the number of patients with embryos exhibiting a heartbeat on TVUS 4 to 5 weeks after embryo transfer divided by the number of cycles $\times 100$. The miscarriage rate was defined as the percentage of patients with clinical pregnancy who could not continue a pregnancy at 20 weeks of gestation. The live birth rate was defined as the percentage of patients with clinical pregnancy who delivered a live birth. Multiple pregnancy rates were defined as the percentage of patients with clinical pregnancy who delivered more than one live birth.

\section{Variables and Data Sources}

For most of the assessed parameters, the unit of analysis was a woman who started COS. However, the unit of analysis was pregnant women for subjects who presented miscarriage, live birth, and multiple pregnancies. The primary endpoints of this study were clinical pregnancy, miscarriage, live birth and multiple pregnancy rates. The following parameters were assessed: age, body mass index (BMI), duration of infertility, indication for ICSI, baseline AFC, number of retrieved oocytes, and number of mature oocytes (MII). The characteristics of COS included duration, total dose of recombinant follicle stimulating hormone (r-FSH), GnRH agonist versus antagonist protocols, and cycles with CC. Other parameters included number of suspended cycles due to poor response, numbers of cycles with embryo transfer and top quality embryo transfer, as well as numbers of cycles with oocyte and embryo cryopreservation, and number of positive pregnancy tests.

\section{Potential Sources of Bias}

In order to avoid selection bias, we considered eligible all women starting COS for IVF/ICSI during the study period who had TSH serum concentrations in their medical records, and that were not using levothyroxine. For patients undergoing more than one cycle during the study period, only data from the first cycle was included. All included women were analyzed. 


\section{Statistical Analyses}

The number of women undergoing COS for IVF/ICSI during the study period who fulfilled the eligibility criteria determined the sample size. The normality of distribution of continuous variables was analyzed by the Kolmogorov-Smirnov test. Continuous variables with normal distribution were summarized as mean \pm standard deviation (SD) and compared among groups by ANOVA. Continuous variables without normal distribution were summarized as median (interquartile range) and compared by Kruskal-Wallis tests. Binary data were presented as ratio and proportion, and compared by Chi-squared $\left(x^{2}\right)$ tests. The level of significance was defined as $p<0.05$. Statistical analyzes were performed using the Statistical Package for Social Sciences software (SPSS, version 18.0, SPSS Inc., Chicago, IL, US).

As an additional analysis, the power of this study to detect differences of $10 \%$ in clinical pregnancy and live birth rates among women with TSH $<2.5 \mathrm{mIU} / \mathrm{L}$ and TSH $\geq 2.5 \mathrm{mIU} / \mathrm{L}$ was determined.

\section{Results}

\section{Participants}

During the study period, 787 women underwent IVF/ICSI in our clinic. Sixty patients were excluded due to the absence of TSH measurements, and 77 were excluded because they were using levothyroxine for the treatment of hypothyroidism. All 650 women were followed until a negative pregnancy test or the end of pregnancy.

\section{Descriptive Data}

The prevalence of patients presenting elevated concentrations of TSH was of $5.07 \%$ (using a TSH threshold of $4.0 \mathrm{mIU} /$ L) and $29.99 \%$ (using a threshold of $2.5 \mathrm{mIU} / \mathrm{L}$ ). Of the 650 included patients, 455 (70.0\%) had TSH $<2.5 \mathrm{mIU} / \mathrm{L}, 162$ (24.92\%) had TSH concentrations of 2.5-4.0 mIU/L, and 33 (5.07\%) had TSH $>4.0 \mathrm{mIU} / \mathrm{L}$ and $<10.0 \mathrm{mIU} / \mathrm{L}$ ( - Table 1 ). None of the patients had TSH concentrations $>10.0 \mathrm{mIU} / \mathrm{L}$. The time between TSH measurement and the cycle was reported in - Table 1. Indications for ICSI included ovulatory disorders (2.92\%); endometriosis (15.69\%); male infertility (31.12\%); tubal factor (10.15\%); combined factors of subfertility (29.07\%); and unexplained infertility (12.46\%) (-Table 1).

The three subgroups were similar in age, weight, height, BMI, duration of infertility, indications for ICSI and AFC ( - Table 1). The distribution of COS protocols did not differ significantly among the three groups (- Table 2 ).

\section{Main Results}

Parameters of ovarian response were similar in the three subgroups, including total dose of r-FSH used during the COS, length of COS, number of retrieved oocytes, and number of mature oocytes (MII) (-Table 2). Moreover, there was no significant difference in cycles suspended due to poor response, cycles with embryo transfer, cycles with top quality embryo transfer, cycles with oocyte cryopreservation and cycles with embryo cryopreservation (-Table 3 ). Similar reproductive outcomes were observed among these three

Table 1 Characteristics of the patients included in the study

\begin{tabular}{|l|l|l|l|l|}
\hline & $\begin{array}{l}\text { Group 1 } \\
\text { TSH }<2.5 \mathrm{mIU} / \mathrm{L}\end{array}$ & $\begin{array}{l}\text { Group 2 } \\
\text { TSH 2.5-4.0 mIU/L }\end{array}$ & $\begin{array}{l}\text { Group 3 } \\
\text { TSH 4.0-10 mIU/L }\end{array}$ & \\
\cline { 2 - 5 } & $\mathbf{( n = 4 5 5 )}$ & $(\boldsymbol{n}=162)$ & $(\boldsymbol{n}=33)$ & $p$ \\
\hline TSH (mIU/L) & $1.5(1.1-1.9)$ & $2.9(2.7-3.4)$ & $4.4(4.1-4.6)$ & $<0.001$ \\
\hline Interval between TSH dosage and cycle (months) & $8(4-18)$ & $8(3-13)$ & $6(1-12)$ & 0.23 \\
\hline Age (years) & $35(31-38)$ & $35(32-38)$ & $35(31-39)$ & 0.36 \\
\hline Duration of subfertility (months) & $60(38-92)$ & $54(30.3-86)$ & $60.5(36.3-91.8)$ & 0.26 \\
\hline Weight $(\mathrm{kg})$ & $64(57-73)$ & $64(57.9-72.3)$ & $64.7(53.3-74.1)$ & 0.86 \\
\hline Height (m) & $1.63(1.58-1.67)$ & $1.64(1.59-1.68)$ & $1.62(1.6-1.65)$ & 0.46 \\
\hline BMI $\left(\mathrm{kg} / \mathrm{m}^{2}\right)$ & $24.2(21.6-27.4)$ & $24(21.9-27.3)$ & $24.2(21.2-27.3)$ & 0.94 \\
\hline AFC & $10(6-18)$ & $10(6-17)$ & $12(6-18)$ & 0.62 \\
\hline Causes of subfertility & $n(\%)$ & $n(\%)$ & $n(\%)$ & 0.90 \\
\hline Ovulatory factor & $15(3.3)$ & $3(1.9)$ & $1(3)$ & \\
\hline Endometriosis & $71(15.6)$ & $28(17.3)$ & $3(9.1)$ & \\
\hline Male Factor & $136(29.9)$ & $46(28.4)$ & $11(33.3)$ & \\
\hline Tubal factor & $42(9.2)$ & $20(12.3)$ & $4(12.1)$ & \\
\hline Combined factors & $136(29.9)$ & $43(26.5)$ & $10(30.3)$ & \\
\hline Unexplained & $55(12.1)$ & $22(13.6)$ & $4(12.1)$ & \\
\hline
\end{tabular}

Abbreviations: AFC, antral follicle count; BMI, body mass index; TSH, thyroid-stimulating hormone.

Notes: TSH, age, duration of subfertility, weight, height, BMI and AFC are reported as median (interquartile range).

$p$ determined by either Kruskal-Wallis or Chi-squared test. 
Table 2 Characteristics of controlled ovarian stimulation (COS) and parameters related to ovarian response

\begin{tabular}{|c|c|c|c|c|}
\hline & $\begin{array}{l}\text { Group } 1 \\
\text { TSH }<2.5 \mathrm{mIU} / \mathrm{L}\end{array}$ & $\begin{array}{l}\text { Group } 2 \\
\text { TSH } 2.5-4.0 \mathrm{mIU} / \mathrm{L}\end{array}$ & $\begin{array}{l}\text { Group } 3 \\
\text { TSH 4.0-10 } \mathrm{mIU} / \mathrm{L}\end{array}$ & \\
\hline & $(n=455)$ & $(n=162)$ & $(n=33)$ & $p$ \\
\hline COS protocol & & & & 0.77 \\
\hline Antagonist, $n(\%)$ & $292(64.2)$ & $108(66.7)$ & $21(63.6)$ & \\
\hline Agonist, $n(\%)$ & $100(22)$ & $32(19.8)$ & $9(27.3)$ & \\
\hline $\mathrm{CC}+$ Antagonist, $n(\%)$ & $63(13.8)$ & $22(13.6)$ & $3(9.1)$ & \\
\hline Total dose of FSH (IU) & $1650(1,200-2,325)$ & $1,600(1,213-2,225)$ & $1,427(1,206-1,856)$ & 0.08 \\
\hline Length of COS (days) & $9(8-11)$ & $9(8-11)$ & $9(8-10.8)$ & 0.83 \\
\hline Number of retrieved oocytes & $5(3-10)$ & $6(2-10)$ & $5(3-9)$ & 0.88 \\
\hline Number of mature oocytes (MII) & $4(2-7)$ & $4(2-7.5)$ & $3.5(2-6)$ & 0.67 \\
\hline Suspension due to poor response, $n$ (\%) & $19(4.2)$ & $5(3.1)$ & $2(6.1)$ & 0.69 \\
\hline
\end{tabular}

Abbreviations: CC, clomiphene citrate; COS, controlled ovarian stimulation; FSH, follicle-stimulating hormone; IU, international unities; MII, mature oocytes in metaphase II; TSH, thyroid-stimulating hormone.

Notes: Total dose of FSH, length of COS, suspension due to poor response, oocytes retrieved, and mature oocytes reported as median (interquartile range). $p$ determined either by Kruskal-Wallis or Chi-squared test.

groups, including clinical pregnancy, live birth, miscarriage, and multiple pregnancy rates (-Table $\mathbf{3}$ ).

\section{Additional Analysis}

The present study had a power of $80 \%$ to detect a difference of $10 \%$ in clinical pregnancy rates and live birth rates among women with $\mathrm{TSH}<2.5 \mathrm{mIU} / \mathrm{L}$ and $\geq 2.5 \mathrm{mIU} / \mathrm{L}$.

\section{Comment}

This study showed that women undergoing COS for ARTs had similar reproductive outcomes, including live birth, clinical pregnancy, miscarriage, and multiple pregnancy rates, regardless of serum TSH concentrations $(<2.5 \mathrm{mIU} / \mathrm{L} ; 2.5-4.0$ $\mathrm{mIU} / \mathrm{L}$; and $4.0-10.0 \mathrm{mIU} / \mathrm{L}$ ). The response to $\mathrm{COS}$, as evaluated by the total dosage of FSH, the duration of $\mathrm{COS}$ and the number of retrieved and mature oocytes, was also similar among these groups.

Concentrations of $\mathrm{TSH}>4.0 \mathrm{mIU} / \mathrm{L}$ were considered altered in the present study, reflecting concerns regarding overdiagnosis and overtreatment when the threshold of $2.5 \mathrm{mIU} / \mathrm{L}$ is chosen. Moreover, there is insufficient evidence that TSH concentrations between 2.5 and $4.0 \mathrm{mIU} / \mathrm{L}$ affect

Table 3 Reproductive outcomes of assisted reproduction cycles

\begin{tabular}{|l|l|l|l|l|}
\hline \multirow{2}{*}{} & $\begin{array}{l}\text { Group 1 } \\
\text { TSH }<2.5 \mathrm{mIU} / \mathrm{L}\end{array}$ & $\begin{array}{l}\text { Group 2 } \\
\text { TSH 2.5-4.0 mIU/L }\end{array}$ & $\begin{array}{l}\text { Group 3 } \\
\text { TSH 4.0-10 mIU/L }\end{array}$ \\
\cline { 2 - 5 } & $(\boldsymbol{n}=455)$ & $(\boldsymbol{n}=162)$ & $(\boldsymbol{n}=33)$ \\
\hline Cycles with fresh embryo transfer, $n(\%)$ & $369(81.1)$ & $136(84)$ & $24(72.7)$ & 0.31 \\
\hline Cycles with fresh top quality embryo transfer, $n(\%)$ & $214(47)$ & $75(46.3)$ & $14(42.4)$ \\
\hline Cycles with oocyte cryopreservation, $n(\%)$ & $20(4.4)$ & $4(2.5)$ & $2(6.1)$ & 0.87 \\
\hline Cycles with embryo cryopreservation, $n(\%)$ & $183(40.2)$ & $63(38.9)$ & $12(36.4)$ & 0.46 \\
\hline Positive pregnancy test, $n(\%)$ & $133(29.2)$ & $52(32.1)$ & $9(27.3)$ \\
\hline Clinical pregnancy rate, $n(\%)$ & $111(24.4)$ & $42(25.9)$ & $8(24.2)$ \\
\hline Live birth rate, $n(\%)$ & $92(20.2)$ & $36(22.2)$ & $7(21.2)$ \\
\hline Miscarriage rate, $n(\%)$ & $19(17.1)$ & $6(14.3)$ & 0.75 \\
\hline Multiple pregnancy rate, $n(\%)$ & $30(27)$ & $9(21.4)$ & 0.93 \\
\hline
\end{tabular}

Abbreviation: TSH: thyroid-stimulating hormone.

Notes: Clinical pregnancy rate: number of patients with embryos exhibiting a heartbeat on transvaginal ultrasound (TVUS) 4 to 5 weeks after embryo transfer divided by the number of cycles $\times 100$.

Miscarriage rate: number of patients who miscarried divided by the number of patients who had clinical pregnancy $\times 100$.

Live birth rate: number of patients who delivered a live birth divided by the number of patients who had clinical pregnancy $\times 100$.

Multiple pregnancy rates: number of patients who delivered more than one live birth divided by the number of patients who had clinical pregnancy $\times 100$.

$p$ determined by Chi-squared test. 
pregnancy and miscarriage rates. ${ }^{7,24}$ Data to support treating patients with TSH concentrations between $2.5 \mathrm{mIU} / \mathrm{L}$ and 4.0-4.5 mIU/L are scarce, ${ }^{7}$ and only a few studies have evaluated the association between periconceptional TSH concentration and pregnancy outcomes among euthyroid patients. ${ }^{25}$ In the present study, clinical pregnancy, miscarriage and live birth rates were similar when $2.5 \mathrm{mIU} / \mathrm{L}$ and 4.0 $\mathrm{mIU} / \mathrm{L}$ were used as TSH cut-off values, which was consistent with previous findings. ${ }^{14,26-30}$ Regarding miscarriage, the ASRM's new guideline points that there is evidence that $\mathrm{TSH}>4.0 \mathrm{mIU} / \mathrm{L}$ is associated with an increase in miscarriage rates. ${ }^{7}$ As seen in the present study, Karmon et $\mathrm{al}^{25}$ found similar clinical pregnancy and delivery rates among women with TSH concentrations of 0.4-2.49 mIU/L and 2.5$4.99 \mathrm{mIU} / \mathrm{L}$ undergoing intrauterine insemination.

Guidelines of the American Association of Clinical Endocrinologists (AACE) and the ATA, ${ }^{31}$ and those of the Endocrine Society ${ }^{3}$ recommend that infertile patients undergoing ARTs must be treated with levothyroxine to maintain TSH concentrations $<2.5 \mathrm{mIU} / \mathrm{L}$. In this study, $24.92 \%$ of women undergoing IVF/ICSI had TSH concentrations between 2.5 and $4.0 \mathrm{mIU} / \mathrm{L}$. Although retrospective studies have shown that untreated women were at an increased risk of adverse pregnancy outcomes, few well-designed studies have evaluated whether these patients would have benefited from levothyroxine treatment., ${ }^{4,5}$ Moreover, until very recently there was no consensus about measuring TSH in asymptomatic infertile women. ${ }^{8,9}$ In the present study, reproductive outcomes were not compromised in women with TSH $\geq 2.5$ and $<10 \mathrm{mIU} / \mathrm{L}$ undergoing ARTs. Nothing can be said about reproductive outcomes in patients presenting TSH concentrations above $10.0 \mathrm{mIU} / \mathrm{L}$, once none of the included patients in this study presented them.

Although human reproduction societies have reported that subfertile women are no more likely to have thyroid disease, ${ }^{7,9}$ the Endocrine Society has stated that the prevalence of thyroid disease is 1 to $43 \%$ higher in subfertile patients. ${ }^{3}$ In our study, the prevalence of patients presenting concentrations of TSH between 4.0 and $10.0 \mathrm{mIU} / \mathrm{L}$ was of $5.07 \%(33 / 650)$. If the threshold of TSH is lowered to $2.5 \mathrm{mIU} / \mathrm{L}$, it will result in a prevalence of $30 \%$, more than a 5 -fold increase. ${ }^{14}$

Our study is limited by its retrospective design. Serum TSH concentrations were not available in $\sim 8 \%$ of the women who underwent ARTs in the study period. However, until very recently, there was no consensus about the routine assessment of TSH concentrations for asymptomatic infertile patients according to the treatment guidelines for ARTs. ${ }^{8,9}$ In the present study, assay bias should be taken into account, once measurements of TSH were not standardized. ${ }^{32}$ TSH concentrations were measured by ultra-sensitive methodology, but once data were obtained by reviewing medical records, it was not possible to mention information regarding the coefficient of variation of the assays. Ideally, for each patient, TSH concentration should have been assessed more than once to exclude laboratory errors or transient elevations of TSH to make an adequate diagnosis. Free thyroxine concentrations were not available in the medical records of the majority of the patients in this cohort, but in asymptomatic patients with mildly elevated TSH concentrations the yield of this test is low. ${ }^{27}$ Our findings cannot be generalized, but they may encourage large prospective studies evaluating the potential impact of TSH concentrations on reproductive outcomes after ARTs.

In conclusion, response to COS, live birth, and miscarriage rates were not worse in women with elevated TSH concentrations (2.5-10.0 mIU/L) undergoing IVF/ICSI. These findings reinforce the uncertainties related to the impact of elevated concentrations of TSH on reproductive outcomes in women undergoing COS for ARTs, and the need for welldesigned prospective studies evaluating this important issue.

\section{Acknowledgments}

The study was performed in a fertility clinic at the university hospital of the Faculdade de Medicina de Ribeirão Preto, University of São Paulo, Ribeirão Preto, Brazil.

Marcela Coelho Neto received financial support from a scholarship granted by Coordenação de Aperfeiçoamento de Pessoal de Nível Superior (CAPES). The other authors received a salary from their institutions and were funded by two Brazilian official agencies: Conselho Nacional de Desenvolvimento Científico e Tecnológico (CNPq) and Fundação de Apoio ao Ensino, Pesquisa e Assistência (FAEPA). The funders had no role in the design of the study, data collection and analysis, decision to publish, or preparation of the manuscript.

The authors would like to thank the staff of the Laboratório de Reprodução Assistida, particularly Sandra Aparecida Cavichiollo, Marisa Blanco, Maria Cristina Picinato, Cristiana Padovan Ribas and Ricardo Perussi e Silva, for technical assistance.

\section{References}

1 Unuane D, Tournaye H, Velkeniers B, Poppe K. Endocrine disorders \& female infertility. Best Pract Res Clin Endocrinol Metab 2011; 25(6):861-873

2 Poppe K, Velkeniers B, Glinoer D. The role of thyroid autoimmunity in fertility and pregnancy. Nat Clin Pract Endocrinol Metab 2008;4(7):394-405

3 De Groot L, Abalovich M, Alexander EK, et al. Management of thyroid dysfunction during pregnancy and postpartum: an Endocrine Society clinical practice guideline. J Clin Endocrinol Metab 2012;97(8):2543-2565

4 van den Boogaard E, Vissenberg R, Land JA, et al. Significance of (sub)clinical thyroid dysfunction and thyroid autoimmunity before conception and in early pregnancy: a systematic review. Hum Reprod Update 2011;17(5):605-619

5 Stagnaro-Green A, Abalovich M, Alexander E, et al; American Thyroid Association Taskforce on Thyroid Disease During Pregnancy and Postpartum. Guidelines of the American Thyroid Association for the diagnosis and management of thyroid disease during pregnancy and postpartum. Thyroid 2011;21(10):1081-1125

6 Velkeniers B, Van Meerhaeghe A, Poppe K, Unuane D, Tournaye H, Haentjens P. Levothyroxine treatment and pregnancy outcome in women with subclinical hypothyroidism undergoing assisted 
reproduction technologies: systematic review and meta-analysis of RCTs. Hum Reprod Update 2013;19(3):251-258

7 Practice Committee of the American Society for Reproductive Medicine. Subclinical hypothyroidism in the infertile female population: a guideline. Fertil Steril 2015;104(3):545-553

8 Practice Committee of American Society for Reproductive Medicine. Diagnostic evaluation of the infertile female: a committee opinion. Fertil Steril 2012;98(2):302-307

9 National Institute for Health and Care Excellence (NICE) [Internet]. Fertility: assessment and treatment for people with fertility problems: clinical guideline. 2013 [cited 2015 May 12]. Available from: $<$ https://www.nice.org.uk/guidance/cg156/resources/fertilityproblems-assessment-and-treatment-35109634660549>

10 Hollowell JG, Staehling NW, Flanders WD, et al. Serum TSH, T(4), and thyroid antibodies in the United States population (1988 to 1994): National Health and Nutrition Examination Survey (NHANES III). J Clin Endocrinol Metab 2002;87(2):489-499

11 Kim CH, Ahn JW, Kang SP, Kim SH, Chae HD, Kang BM. Effect of levothyroxine treatment on in vitro fertilization and pregnancy outcome in infertile women with subclinical hypothyroidism undergoing in vitro fertilization/intracytoplasmic sperm injection. Fertil Steril 2011;95(5):1650-1654

12 Magri F, Capelli V, Gaiti M, et al. Impaired outcome of controlled ovarian hyperstimulation in women with thyroid autoimmune disease. Thyroid 2013;23(10):1312-1318

13 Mintziori G, Goulis DG, Gialamas E, et al. Association of TSH concentrations and thyroid autoimmunity with IVF outcome in women with TSH concentrations within normal adult range. Gynecol Obstet Invest 2014;77(2):84-88

14 Reh A, Grifo J, Danoff A. What is a normal thyroid-stimulating hormone (TSH) level? Effects of stricter TSH thresholds on pregnancy outcomes after in vitro fertilization. Fertil Steril 2010;94(7): 2920-2922

15 Busnelli A, Somigliana E, Benaglia L, Sarais V, Ragni G, Fedele L. Thyroid axis dysregulation during in vitro fertilization in hypothyroid-treated patients. Thyroid 2014;24(11):1650-1655

16 Gracia CR, Morse CB, Chan G, et al. Thyroid function during controlled ovarian hyperstimulation as part of in vitro fertilization. Fertil Steril 2012;97(3):585-591

17 Reinblatt S, Herrero B, Correa JA, et al. Thyroid stimulating hormone levels rise after assisted reproductive technology. J Assist Reprod Genet 2013;30(10):1347-1352

18 Benaglia L, Busnelli A, Somigliana E, et al. Incidence of elevation of serum thyroid-stimulating hormone during controlled ovarian hyperstimulation for in vitro fertilization. Eur J Obstet Gynecol Reprod Biol 2014;173:53-57

19 Surks MI, Ortiz E, Daniels GH, et al. Subclinical thyroid disease: scientific review and guidelines for diagnosis and management. JAMA 2004;291(2):228-238

20 Martins WP, Vieira CV, Teixeira DM, Barbosa MA, Dassunção LA, Nastri CO. Ultrasound for monitoring controlled ovarian stimula- tion: a systematic review and meta-analysis of randomized controlled trials. Ultrasound Obstet Gynecol 2014;43(1):25-33

21 Figueiredo JB, Nastri CO, Vieira AD, Martins WP. Clomiphene combined with gonadotropins and $\mathrm{GnRH}$ antagonist versus conventional controlled ovarian hyperstimulation without clomiphene in women undergoing assisted reproductive techniques: systematic review and meta-analysis. Arch Gynecol Obstet 2013;287(4):779-790

22 Peñarrubia J, Fábregues F, Manau D, et al. Previous cycle cancellation due to poor follicular development as a predictor of ovarian response in cycles stimulated with gonadotrophin-releasing hormone agonist-gonadotrophin treatment. Hum Reprod 2005; 20(3):622-628

23 Alpha Scientists in Reproductive Medicine and ESHRE Special Interest Group of Embryology. The Istanbul consensus workshop on embryo assessment: proceedings of an expert meeting. Hum Reprod 2011;26(6):1270-1283

24 Weghofer A, Barad DH, Darmon S, Kushnir VA, Gleicher N. What affects functional ovarian reserve, thyroid function or thyroid autoimmunity? Reprod Biol Endocrinol 2016;14(1):26

25 Karmon AE, Batsis M, Chavarro JE, Souter I. Preconceptional thyroid-stimulating hormone levels and outcomes of intrauterine insemination among euthyroid infertile women. Fertil Steril 2015;103(1):258-63.e1

26 Chai J, Yeung WY, Lee CY, Li HW, Ho PC, Ng HY. Live birth rates following in vitro fertilization in women with thyroid autoimmunity and/or subclinical hypothyroidism. Clin Endocrinol (Oxf) 2014;80(1):122-127

27 Michalakis KG, Mesen TB, Brayboy LM, et al. Subclinical elevations of thyroid-stimulating hormone and assisted reproductive technology outcomes. Fertil Steril 2011;95(8):2634-2637

28 Aghahosseini M, Asgharifard H, Aleyasin A, Tehrani Banihashemi A. Effects of Thyroid Stimulating Hormone (TSH) level on clinical pregnancy rate via In Vitro Fertilization (IVF) procedure. Med J Islam Repub Iran 2014;28:46

29 Green KA, Werner MD, Franasiak JM, Juneau CR, Hong KH, Scott RT Jr. Investigating the optimal preconception TSH range for patients undergoing IVF when controlling for embryo quality. J Assist Reprod Genet 2015;32(10):1469-1476

30 Weghofer A, Himaya E, Kushnir VA, Barad DH, Gleicher N. The impact of thyroid function and thyroid autoimmunity on embryo quality in women with low functional ovarian reserve: a casecontrol study. Reprod Biol Endocrinol 2015;13:43

31 Garber JR, Cobin RH, Gharib H, et al; American Association of Clinical Endocrinologists and American Thyroid Association Taskforce on Hypothyroidism in Adults. Clinical practice guidelines for hypothyroidism in adults: cosponsored by the American Association of Clinical Endocrinologists and the American Thyroid Association. Endocr Pract 2012;18(6):988-1028

32 Beckett G, MacKenzie F. Thyroid guidelines - are thyroid-stimulating hormone assays fit for purpose? Ann Clin Biochem 2007; 44(Pt 3):203-208 